\title{
Shape-Controlled Syntheses of Magnetite Microparticles and Their Magnetorheology
}

\author{
Hiroya Abe ${ }^{1, *}$, Takashi Naka ${ }^{2}$, Kazuyoshi Sato ${ }^{3}$, Yoshikazu Suzuki ${ }^{4}$ and Masami Nakano ${ }^{5}$ (D) \\ 1 Joining and Welding Research Institute, Osaka University, Osaka 567-0047, Japan \\ 2 National Institute for Materials Science, Ibaraki 305-0047, Japan \\ 3 Graduate School of Science \& Technology, Gunma University, Gunma 376-8515, Japan \\ 4 Faculty of Pure and Applied Sciences, University of Tsukuba, Ibaraki 305-8573, Japan \\ 5 New Industry Creation Hatchery Center, Tohoku University, Sendai 980-8577, Japan \\ * Correspondence: h-abe@jwri.osaka-u.ac.jp; Tel.: +81-66-879-4360
}

Received: 30 May 2019; Accepted: 23 July 2019; Published: 24 July 2019

\begin{abstract}
Magnetic microspheres in a concentrated suspension can be self-assembled to form chain structures under a magnetic field, resulting in an enhanced viscosity and elasticity of the suspension (i.e., the magnetorheological (MR) effect). Recently, interest has been raised about the relationship between nonspherical particles, such as octahedral particles and the MR effect. However, experimental studies have not made much progress toward clarifying this issue due to the difficulty associated with synthesizing microparticles with well-defined shapes and sizes. Here, we presented a method for the shape-controlled synthesis of magnetite $\left(\mathrm{Fe}_{3} \mathrm{O}_{4}\right)$ microparticles and investigated the MR effects of two suspensions prepared from the two shape-controlled samples of $\mathrm{Fe}_{3} \mathrm{O}_{4}$ microparticles. Our method, which was based on the polyol method, enabled the preparation of spherical and octahedral $\mathrm{Fe}_{3} \mathrm{O}_{4}$ microparticles with similar sizes and magnetic properties, through a reduction of $\alpha-\mathrm{FeOOH}$ in a mixed solvent of ethylene glycol (a polyol) and water. The water played an important role in both the phase transition $\left(\alpha-\mathrm{FeOOH}\right.$ to $\left.\mathrm{Fe}_{3} \mathrm{O}_{4}\right)$ and the shape control. No substantial difference in the MR effect was observed between an octahedral-particle-based suspension and a spherical-particle-based one. Therefore, in this study, the shape of the microparticles did not strongly influence the MR effect, i.e., the properties of the chain structures.
\end{abstract}

Keywords: magnetite; shape-controlled; octahedral-shape; microparticle; magnetorheology

\section{Introduction}

A magnetorheological (MR) fluid is a magneto-responsive soft material that undergoes a reversible transition from a liquid-like to a near-solid state under the influence of an external magnetic field (i.e., the MR effect) [1]. This property makes MR fluids good candidates for applications in mechanical systems such as passive MR dampers [2], haptic interfaces [3], and human-friendly robots [4]. This material is a two-phase system consisting of magnetic particles and a carrier liquid [1]. The mechanism responsible for the MR effect is an attractive interaction between the induced magnetic dipoles, which causes the suspended particles to form chain structures aligned parallel to an applied magnetic field. Such chain structures can substantially increase the viscosity and yield stress of an MR fluid on a millisecond timescale.

Micron-sized iron particles with a spherical shape are used as MR fluids $[1,5,6]$. If the particles are nano-sized, Brownian motion prevents the formation of chain structures $[7,8]$. In fact, ferrofluids, which are colloidal dispersions of magnetic nanoparticles approximately $10 \mathrm{~nm}$ in diameter, exhibit a weak MR effect because of predominant Brownian motion [8]. As another material for MR fluids, 
magnetite $\left(\mathrm{Fe}_{3} \mathrm{O}_{4}\right)$ particles have been studied because they exhibit better chemical stability against oxidation and are less prone to sedimentation than Fe particles [9-11].

Over the past few decades, much effort has been devoted to synthesizing nanoscale particles with various shapes such as cubic, tetrahedral, and octahedral [12-14]. Consequently, questions have arisen about the relationship between nonspherical particles and the MR effect [15]. Jung et al. synthesized octahedral-shaped $\mathrm{Fe}_{3} \mathrm{O}_{4}$ nanoparticles [16] and expected them to form stronger chain structures than spherical particles due to interparticle friction. This hypothesis was based on the presumption that chains of octahedral-shaped particles would have a larger contact surface than chains of spherical particles. Expecting the same mechanism, Han et al. synthesized triangular-shaped $\mathrm{Fe}_{3} \mathrm{O}_{4}$ nanoparticles [10]. Although MR effects were observed in the two aforementioned fluids, it is unclear if such nanoscale surface contact enhances the MR effects. The use of micron-sized octahedral particles in such investigations might be preferable because they are negligibly influenced by Brownian motion under magnetic fields. However, the development of a simple and reliable method for synthesizing magnetic microparticles with well-defined shapes and sizes remains a challenge.

In this study, we developed a facile polyol-based method for synthesizing shape-controlled $\mathrm{Fe}_{3} \mathrm{O}_{4}$ microparticles. The polyol method can produce microparticles of metals and metal oxides via the reduction of precursors in a polyol solvent (typically ethylene glycol (EG)) [17]. Our modified polyol method enabled the preparation of spherical and octahedral $\mathrm{Fe}_{3} \mathrm{O}_{4}$ microparticles with similar sizes and magnetic properties through reduction of $\alpha$-FeOOH (solid precursor) in a mixed solvent of EG and water. In this method, water plays important roles in both phase transition $\left(\alpha-\mathrm{FeOOH}\right.$ to $\left.\mathrm{Fe}_{3} \mathrm{O}_{4}\right)$ and shape control. Two suspensions were prepared from the spherical and octahedral microparticles, and their MR effects were compared to directly probe the effect of particle shape on the MR effect.

\section{Results}

\subsection{Syntheses of Spherical and Octahedral $\mathrm{Fe}_{3} \mathrm{O}_{4}$ Microparticles}

In this study, $\mathrm{Fe}_{3} \mathrm{O}_{4}$ microparticles were prepared via reduction of $\alpha-\mathrm{FeOOH}$ in a solvent mixture of water-EG at $200{ }^{\circ} \mathrm{C}$. Moreover, their shapes were controlled by varying 9 vol. $\%$ and 12 vol. $\%$ water concentrations of the mixed solvents.

The phase transformation of $\alpha-\mathrm{FeOOH}$ to $\mathrm{Fe}_{3} \mathrm{O}_{4}$ was accompanied by a color change (yellow to black) of the powder during reductive aging of $\alpha-\mathrm{FeOOH}$ in both mixed solvents (Figures 1 and 2). Yellow and black are typical colors of $\alpha$ - $\mathrm{FeOOH}$ and $\mathrm{Fe}_{3} \mathrm{O}_{4}$, respectively [18]. The X-ray diffraction (XRD) patterns of the two black powders demonstrate their crystalline nature, and the peaks match well with the standard reflections for $\mathrm{Fe}_{3} \mathrm{O}_{4}$ (\#019-0629, PDF-2 database, ICDD, Newtown Square, PA, USA). The peaks are sharp and intense, indicating good crystallinity of the samples. Almost no characteristic peaks arising from $\alpha-\mathrm{FeOOH}$ (Figure S1) or other iron oxides or oxyhydroxides were observed. The aging times for 9 vol. \% and 12 vol. \% water concentrations were $24 \mathrm{~h}$ and $48 \mathrm{~h}$, respectively, although the exact aging times needed for the two water concentrations have not yet been examined. The black powder $\left(\mathrm{Fe}_{3} \mathrm{O}_{4}\right)$ was not obtained when aging the yellow powder $(\alpha-\mathrm{FeOOH})$ in only the EG solvent (in the absence of water) even for $72 \mathrm{~h}$ at $200^{\circ} \mathrm{C}$. 


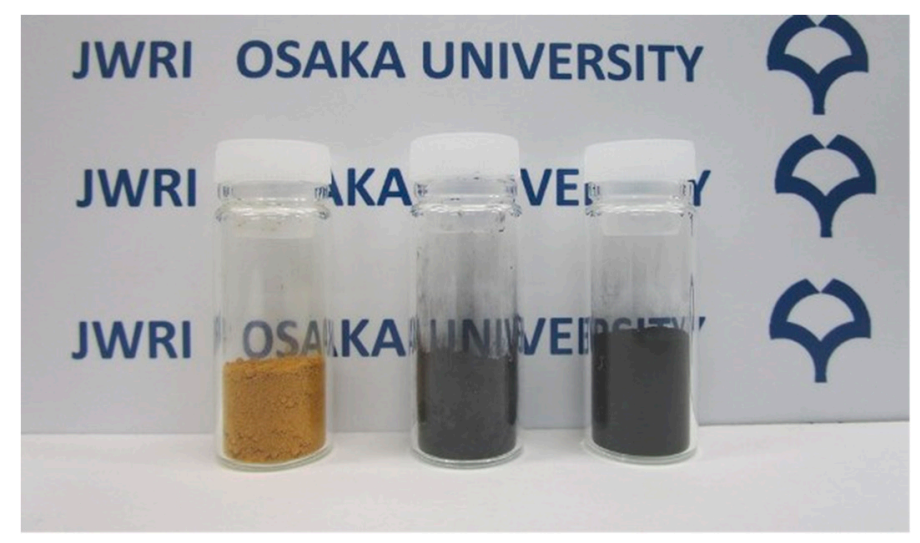

Figure 1. Photographs of (left) $\alpha-\mathrm{FeOOH}$ powder used as a precursor; (center) the product prepared by reducing $\alpha-\mathrm{FeOOH}$ in the mixed solvent with 9 vol. \% water concentration at $200{ }^{\circ} \mathrm{C}$ for $24 \mathrm{~h}$; (right) the product prepared by reducing $\alpha-\mathrm{FeOOH}$ with 12 vol. $\%$ water concentration at $200{ }^{\circ} \mathrm{C}$ for $48 \mathrm{~h}$.

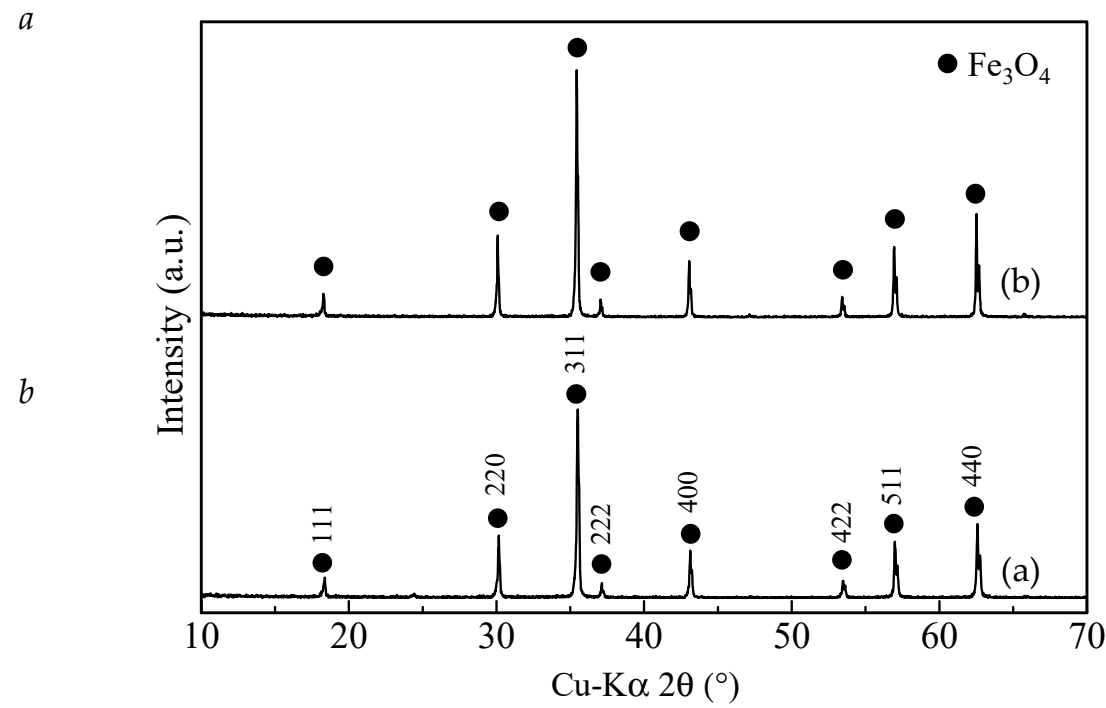

Figure 2. X-ray diffraction patterns of (a) the powder prepared by the reduction of $\alpha$-FeOOH in the mixed solvent with 9 vol. \% water concentration at $200{ }^{\circ} \mathrm{C}$ for $24 \mathrm{~h}$; (b) the powder prepared by reduction of $\alpha$-FeOOH with 12 vol. \% water concentration at $200{ }^{\circ} \mathrm{C}$ for $48 \mathrm{~h}$.

The $\alpha$-FeOOH particles were needle-shaped (Figure S2). They were transformed mostly to spherical and octahedral $\mathrm{Fe}_{3} \mathrm{O}_{4}$ microparticles via aging in EG containing 9 vol. $\%$ and 12 vol. \% water concentration, respectively, as shown in Figure 3. The spherical microparticles featured a relatively narrow size distribution, and their average diameter was $1.00 \pm 0.13 \mu \mathrm{m}$ (Figure S3a). Their surface images reflected the polycrystalline nature (Figure $3 b$ ), indicating that each spherical microparticle comprised small primary grains. The aging time was another important parameter to control the spherical shape because with an increase in aging time, the $\mathrm{Fe}_{3} \mathrm{O}_{4}$ microparticles did not maintain the spherical shape. 

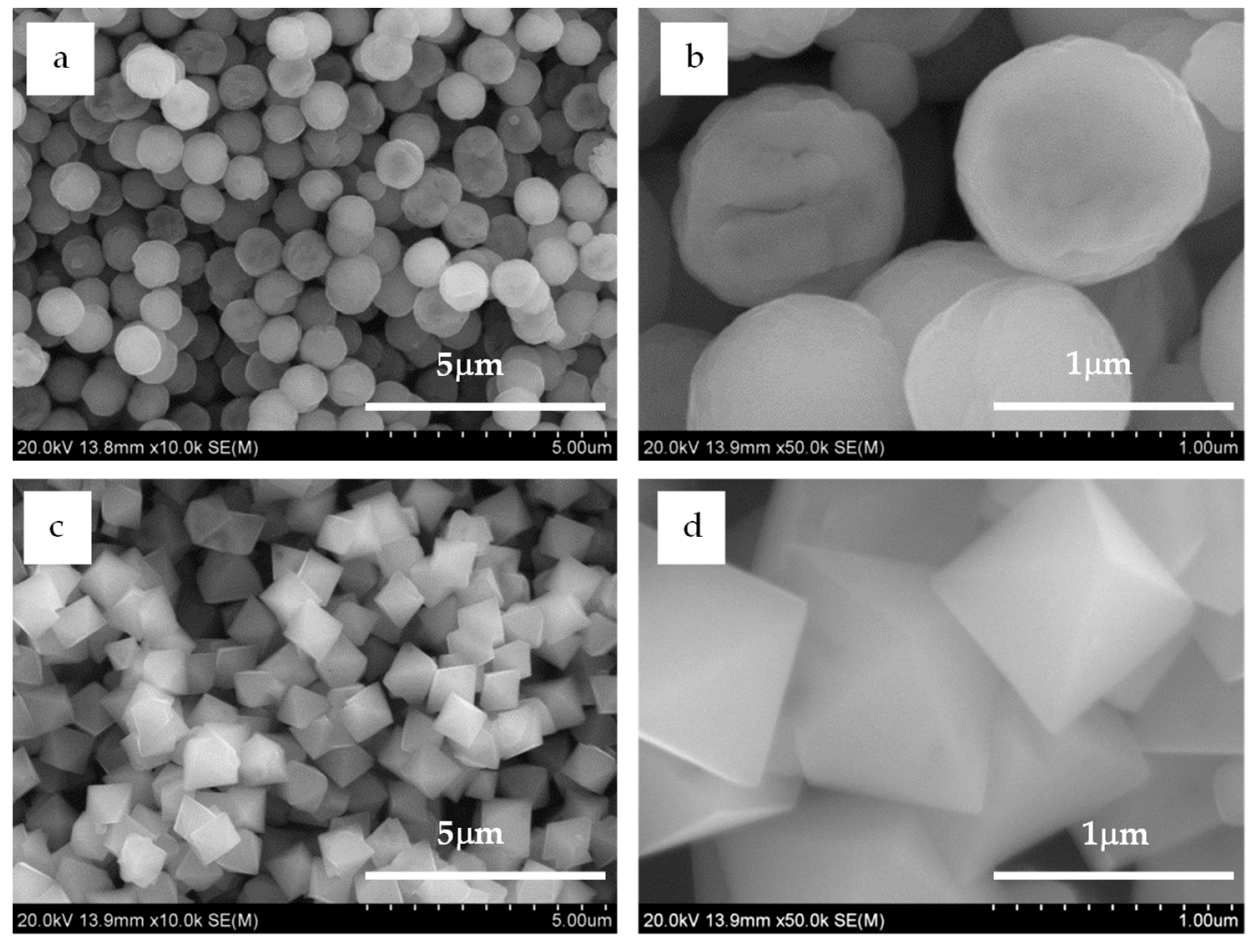

Figure 3. Typical scanning electron microscopy images of the products $(\mathbf{a}, \mathbf{b})$. Spherical $\mathrm{Fe}_{3} \mathrm{O}_{4}$ particles prepared by reduction of $\alpha-\mathrm{FeOOH}$ in the mixed solvent with 9 vol. $\%$ water concentration at $200{ }^{\circ} \mathrm{C}$ for $24 \mathrm{~h}$; (c,d) octahedral $\mathrm{Fe}_{3} \mathrm{O}_{4}$ particles prepared by reduction of $\alpha-\mathrm{FeOOH}$ with 12 vol. \% water concentration at $200{ }^{\circ} \mathrm{C}$ for $48 \mathrm{~h}$.

For the octahedral microparticles, the longest dimension of each particle was measured as it appeared in the scanning electron microscopy images, following the measuring procedure of Vereda et al. [19]. A narrow size distribution was also observed for the octahedral microparticles (Figure S3b), where the average diameter was $1.10 \pm 0.15 \mu \mathrm{m}$-slightly larger than that of the spherical microparticles. The $\mathrm{Fe}_{3} \mathrm{O}_{4}$ microparticles maintained the octahedral shape with increasing aging time. The octahedral shape was the main theoretical morphology [20]; therefore, their shape suggested that each particle was a single crystal.

To characterize the magnetic properties of the synthesized particles, we recorded their magnetization curves at room temperature $(300 \mathrm{~K})$. The curves were almost the same for both the octahedral and spherical $\mathrm{Fe}_{3} \mathrm{O}_{4}$ microparticles, as shown in Figure 4. The curves exhibited very small hysteresis loops that were barely observable at the scale shown in Figure $4 a, b$. However, they were apparent in the magnified image (inset). The saturation magnetizations of the $\mathrm{Fe}_{3} \mathrm{O}_{4}$ microparticles with spherical and octahedral shapes were $80.2 \mathrm{emu} / \mathrm{g}$ and $81.0 \mathrm{emu} / \mathrm{g}$, respectively, and their coercivities were 47 Oe and 36 Oe, respectively. 


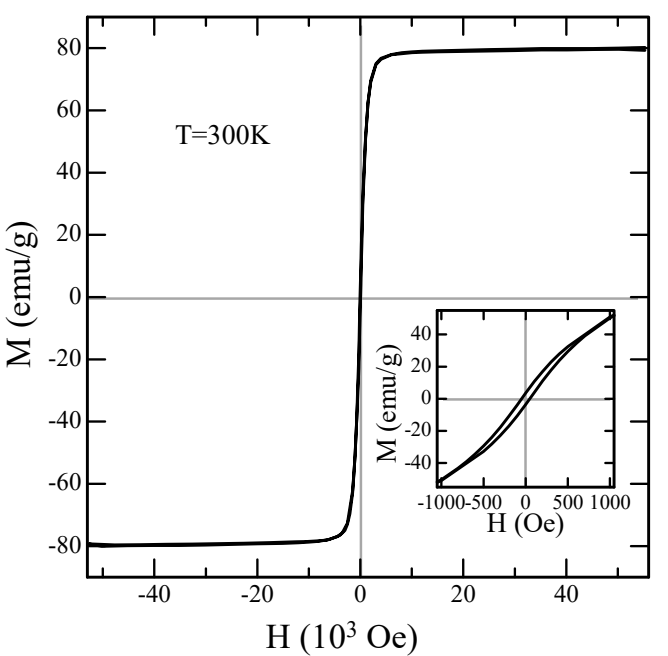

(a)

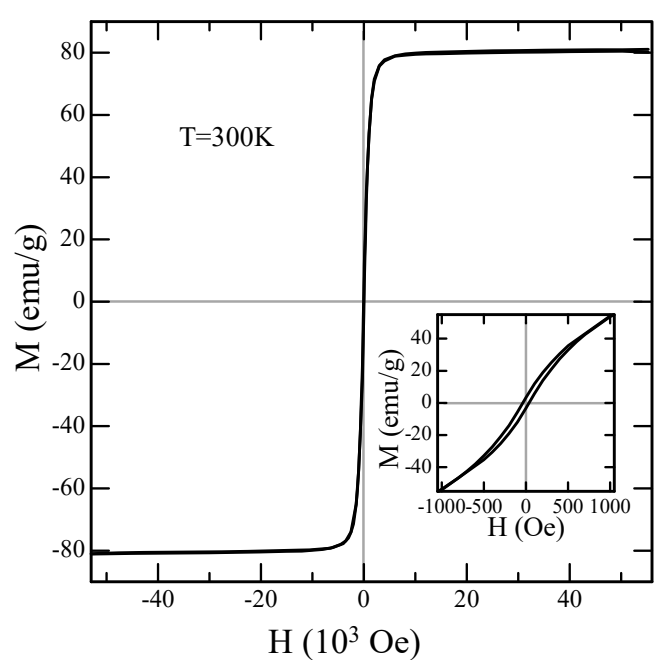

(b)

Figure 4. (a) Mass magnetization $M$ as a function of the applied external magnetic field $\mathrm{H}$ measured for the spherical $\mathrm{Fe}_{3} \mathrm{O}_{4}$ microparticles at $300 \mathrm{~K}$. (b) Mass magnetization for the octahedral $\mathrm{Fe}_{3} \mathrm{O}_{4}$ microparticles.

Thus, the modified polyol process presented here is a straightforward and effective synthesis strategy for preparing spherical and octahedral $\mathrm{Fe}_{3} \mathrm{O}_{4}$ microparticles with similar sizes and magnetic properties. Due to these features, the resulting two shape-controlled microparticles might be an ideal system to directly probe the shape dependency of magnetorheology.

\subsection{Magnetorheology of The Shape-Controlled $\mathrm{Fe}_{3} \mathrm{O}_{4}$ Microparticles}

Suspensions of both the spherical and octahedral $\mathrm{Fe}_{3} \mathrm{O}_{4}$ microparticles were prepared. EG was used as a carrier liquid herein. Figures 5 and 6 show the flow curves of the two suspensions with a solid fraction of $10 \mathrm{vol} . \%$, using a controlled shear-rate test under a range of magnetic flux densities, plotted on a log-log scale. The flow curve provides information about the dependence of the shear stress on the shear rate.

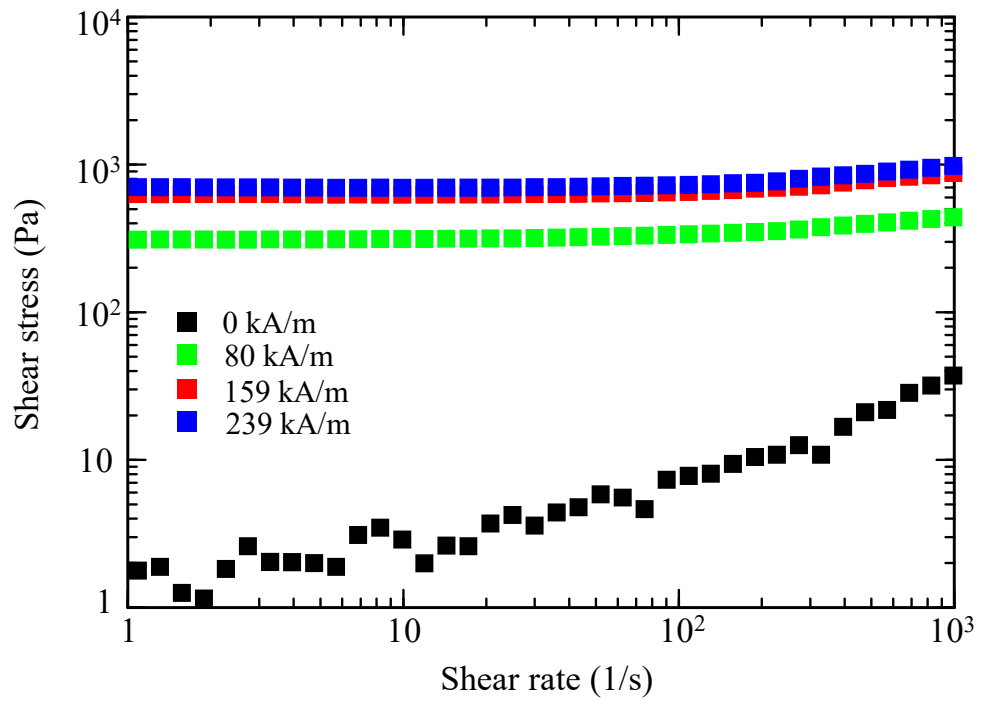

Figure 5. Flow curves under the magnetic fields for a $\mathrm{Fe}_{3} \mathrm{O}_{4}$ suspension (10 vol. \%) containing spherical particles. 


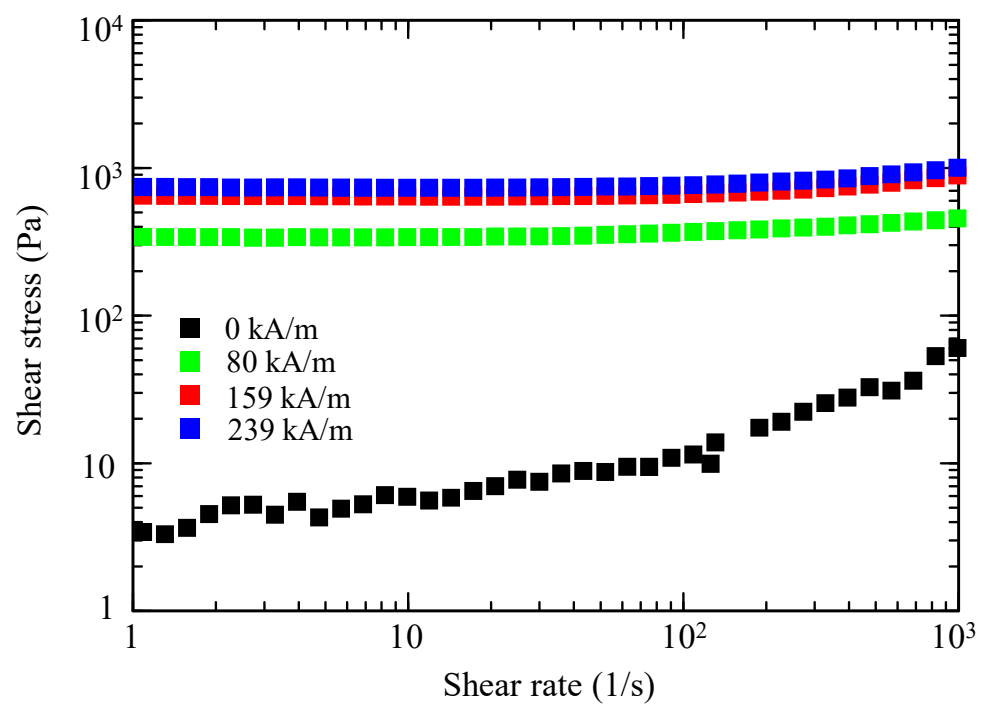

Figure 6. Flow curves under the magnetic fields for a $\mathrm{Fe}_{3} \mathrm{O}_{4}$ suspension (10 vol. \%) containing octahedral particles.

At zero magnetic fields, both fluids exhibited Newtonian-like behavior, where the shear stress increased linearly with increasing shear rate. The shear stress of the octahedral-particle-based MR fluid was slightly higher than that of the spherical-particle-based MR fluid, likely because of the stronger deflection of the flow lines of the fluid flowing around the octahedral particles and the stronger particle-particle interaction among the octahedral particles.

When subjected to a magnetic field, both suspensions showed an increase of their shear stress with increasing magnitude of the magnetic field. Notably, no substantial difference existed in the MR effect between the spherical-based and octahedral-based suspensions. These characteristics were distinctive solid-like behaviors with a clear yield stress. The observed solid-like or plastic behavior can usually be characterized by the Bingham fluid model $[5,16,21]$, which can be explained by the formation of chain-like structures or magnetic particle columns in a fluid [1,5].

In addition, oscillatory shear measurements were performed to further explore the shape dependence. Figure 7 shows the storage moduli $\left(G^{\prime}\right)$ of both suspensions as a function of the shear stress amplitude at different magnetic fields $(80$ and $239 \mathrm{kA} / \mathrm{m})$. The $\mathrm{G}^{\prime}$ values of the suspensions did not differ significantly. In each suspension, $G^{\prime}$ increased as the strength of the magnetic field increased. Pseudoplateaus were observed at low shear stress values, which are referred to as linear viscoelastic regions. $G^{\prime}$ values in this region provide information about the strength of the field-induced chain structures [22]. As the linear viscoelastic $G^{\prime}$ values of the microparticle suspensions were very similar, the strengths of the field-induced spherical and octahedral microparticle structures would be nearly identical. Therefore, the particle shape did not substantially influence the magnetorheology in our comparative studies. 


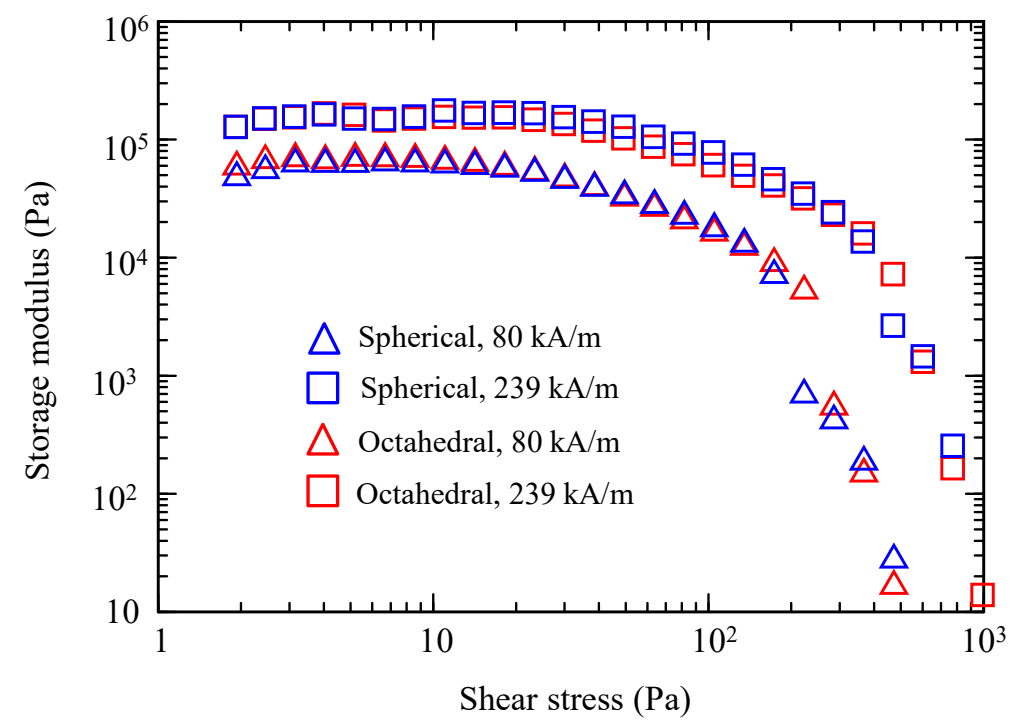

Figure 7. Storage modulus as a function of the shear stress amplitude, for the spherical-based and the octahedral-based suspensions.

\section{Discussion}

\subsection{Synthesis Mechanism}

Figure 8a depicts a simple schematic of the two shape-controlled syntheses of $\mathrm{Fe}_{3} \mathrm{O}_{4}$ microparticles. The two main features in the syntheses were (1) the phase transformation of $\alpha-\mathrm{FeOOH}$ to $\mathrm{Fe}_{3} \mathrm{O}_{4}$ under EG-based reductive aging in the presence of water and (2) the two shape-controls that depend on the water concentration. We, therefore, discuss these two points in this order.

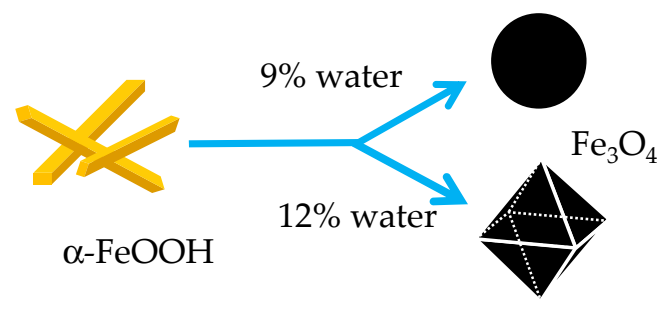

(a)

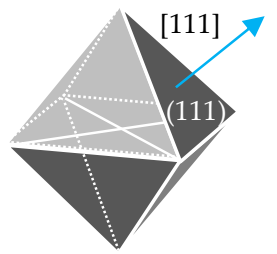

(b)

Figure 8. (a) Schematic of $\mathrm{Fe}_{3} \mathrm{O}_{4}$ with disparate shapes resulting from different water concentrations in the EG-water mixed solvent used in the synthesis; (b) $\mathrm{Fe}_{3} \mathrm{O}_{4}$ octahedron of a single crystal enclosed by eight $\{111\}$ planes. $<111>$ : easy axis of magnetization.

\subsubsection{Phase Transformation}

In the polyol method, particle formation proceeded via solution-specifically, dissolution of the solid precursor, reduction of metal ions to a lower valence state, and precipitation of the resultant solid phase [17]. In this study, the phase transition did not occur in the absence of water. Therefore, the water functioned as a dissolving agent for $\alpha-\mathrm{FeOOH}$. Once the $\mathrm{Fe}^{3+}$ ions were released by dissolution into the solution, $\mathrm{EG}\left(\mathrm{C}_{2} \mathrm{H}_{6} \mathrm{O}_{2}\right)$ partially reduced the $\mathrm{Fe}^{3+}$ ions to $\mathrm{Fe}^{2+}$ ions. Subsequently, $\mathrm{Fe}_{3} \mathrm{O}_{4}$ was precipitated through hydrolysis of a mixture of $\mathrm{Fe}^{3+}$ and $\mathrm{Fe}^{2+}$ ions. According to the literature [17], the main oxidation product of EG in the polyol process is diacetyl $\left(\mathrm{C}_{4} \mathrm{H}_{6} \mathrm{O}_{2}\right)$. Thus, the phase transformation of $\alpha-\mathrm{FeOOH}$ to $\mathrm{Fe}_{3} \mathrm{O}_{4}$ could be described by the following reactions:

$$
\mathrm{FeOOH}+\mathrm{H}_{2} \mathrm{O} \rightarrow \mathrm{Fe}^{3+}+3 \mathrm{OH}^{-}
$$




$$
\begin{gathered}
2\left(\mathrm{C}_{2} \mathrm{H}_{6} \mathrm{O}_{2}\right) \rightarrow 2 \mathrm{e}^{-}+\mathrm{C}_{4} \mathrm{H}_{6} \mathrm{O}_{2}+2 \mathrm{H}_{2} \mathrm{O}+2 \mathrm{H}^{+} \\
6 \mathrm{FeOOH}+6 \mathrm{H}_{2} \mathrm{O}+2\left(\mathrm{C}_{2} \mathrm{H}_{6} \mathrm{O}_{2}\right) \rightarrow 2 \mathrm{Fe}_{3} \mathrm{O}_{4}+\mathrm{C}_{4} \mathrm{H}_{6} \mathrm{O}_{2}+12 \mathrm{H}_{2} \mathrm{O}
\end{gathered}
$$

As $\mathrm{Fe}_{3} \mathrm{O}_{4}$ is a more thermodynamically stable phase than $=\alpha-\mathrm{FeOOH}$, in a reducing environment [23], it could be considered that reactions (1)-(3) proceeded spontaneously.

\subsubsection{Shape Control}

Inorganic particles often assume their thermodynamically favored shapes during slow crystal growth [24]. For $\mathrm{Fe}_{3} \mathrm{O}_{4}$, the thermodynamically favored shape is octahedral [19,20]. $\mathrm{Fe}_{3} \mathrm{O}_{4}$ has an inverse spinel structure with oxygen forming a face-centered cubic (FCC) closed packing. In such FCC crystals, the surface energies for the FCC facets scale accordingly: $\gamma(111)<\gamma(100)<\gamma(101)$, which means that the crystals usually exist as an octahedron surrounded by $\{111\}$ facets (Figure 8b). In our experiments, the octahedral particles were obtained after the aging process in an EG-water solvent with 12 vol. \% water, indicating that this condition would result in a sufficiently slow crystal growth to enable the growth of the octahedral particles.

$\alpha$-FeOOH is very poorly soluble (solubility product $K_{\mathrm{sp}}, \log K_{\mathrm{sp}}<-41$ at $25^{\circ} \mathrm{C}$ [25]). In addition, $\mathrm{EG}$ is diluted by water, i.e., the concentration of the reductant (EG) is lowered. Therefore, the monomers, which are the minimum subunits of bulk $\mathrm{Fe}_{3} \mathrm{O}_{4}$, are considered to be supplied considerably slowly into the reaction system and to be taken up by the preformed nuclei.

The supply rate of the monomers in the presence of 9 vol. \% water would also be slow. However, it must be faster than that in $12 \mathrm{vol}$ \% water because the reductant is less diluted. In fact, the aging time with 9 vol. \% water was shorter than that with 12 vol. \% water. Thermodynamically unstable structures are often obtained at faster growth rates $[24,26]$. In our case, spherical particles with a polycrystalline structure were obtained, which were similar to those synthesized by EG-based reductive aging of $\mathrm{FeCl}_{3} \cdot 6 \mathrm{H}_{2} \mathrm{O}$ in the presence of sodium acetate and a surfactant $[27,28]$ and those prepared by the oxidative aging of $\mathrm{Fe}(\mathrm{OH})_{2}$ in the presence of $\mathrm{KNO}_{3}$ [29].

The observed nearly monodispersed characteristics for both particle types suggest that a burst of nucleation occurs in our synthesis system. The burst of nucleation enables the separation of homogeneous nucleation and growth processes, which is known to be an effective strategy for preparing monodispersed particles [30]. The sufficiently slow supply of monomer as a result of the dissolution of a solid precursor has been demonstrated to result in a burst of nucleation for monodispersed microparticles of iron oxides [29,31,32]. In our study, the slow supply could be achieved by the reductive hydrolysis of $\alpha-\mathrm{FeOOH}$ in solution; notably, changing the supply rate could enable shape control in the absence of a surfactant. The elucidation of the detailed mechanism remains in progress and will be reported in a future study.

To the best of our knowledge, the system reported here is the simplest synthetic system reported for producing $\mathrm{Fe}_{3} \mathrm{O}_{4}$ microparticles. It is attractive because the precursor $(\alpha-\mathrm{FeOOH})$ is inexpensive and the procedure itself is economical because it does not involve additives such as a base for hydrolysis or surfactants for shape control, which enables an easy scale-up. Due to the simplicity of this system, we synthesized sufficient amounts of $\mathrm{Fe}_{3} \mathrm{O}_{4}$ microparticles to prepare MR fluids.

\subsection{Shape Effect on Magnetorheology}

Recently, octahedral particles have been speculated to enhance the MR effect [16,22]. Such magnetic particles would make stronger particle chains than spherical magnetic particles because the chains of the octahedral particles have a larger contact surface [16]. In this system, a remarkable contribution of the interparticle friction is expected. However, the results obtained in the present study indicated that the effect of particle shape appears to be less important.

The $\mathrm{Fe}_{3} \mathrm{O}_{4}$ chosen as a magnetic material herein exhibited magnetocrystalline anisotropy-the $<111>,<110\rangle$, and $<100>$ crystallographic directions corresponded to the easy, intermediate, and hard axes of magnetization, respectively [14]. An octahedral $\mathrm{Fe}_{3} \mathrm{O}_{4}$ particle is enclosed by eight $\{111\}$ 
planes, which are perpendicular to the $\langle 111>$ direction (Figure $8 b$ ). Therefore, when subjected to a magnetic field, octahedral $\mathrm{Fe}_{3} \mathrm{O}_{4}$ particles would form chains along the easy axis by connecting $\{111\}$ faces, leading to a larger contact surface compared with that of spherical particles. In fact, such face-to-face assembled structures have been observed for octahedral $\mathrm{Fe}_{3} \mathrm{O}_{4}$ nanoparticles under a magnetic field [13,14]. However, the MR effect of the octahedral-based and spherical-based suspensions was detected to be almost similar, as shown in Figures 5-7.

The results obtained in this study suggest that a mechanism might exist that made negligible contribution of the interparticle friction in our octahedral-based suspension. This mechanism might be related to particle concentration. Vereda et al. have reported that a $1 \mathrm{vol}$. \% suspension containing faceted particles (predominantly octahedral particles) enhanced the MR effect compared to their spherical-based suspension; however, this MR enhancement decreased as the particle concentration increased to 5 vol. \% [22]. Our particle concentration was 10 vol. \% and almost no enhancements were observed, as mentioned above. We, thus, speculate that the interaction among the magnetic field-aggregated particles, rather than the interparticle friction of the octahedral microparticles, might predominantly cause the viscosity or elasticity to increase at particle concentrations exceeding $10 \mathrm{vol} . \%$.

\section{Materials and Methods}

\subsection{Shape-Controlled Synthesis of $\mathrm{Fe}_{3} \mathrm{O}_{4}$ Microparticles}

All chemicals were of analytical grade and were used as received without further purification. $\alpha$-FeOOH powder $\left(4.26 \mathrm{~g} / \mathrm{cm}^{3}\right)$ was purchased from Kojundo Chemical Laboratory Co., Ltd. (Saitama, Japan). EG was purchased from Kishida Chemical Co., Ltd. (1.11 g/ $\mathrm{cm}^{3}$, Osaka, Japan). Water used in all syntheses was distilled and deionized.

$\mathrm{Fe}_{3} \mathrm{O}_{4}$ microparticles were synthesized via reductive aging of $\alpha$-FeOOH in a mixed solvent of EG and water. The particle shape was controlled by adjusting the water concentration. In a typical procedure for spherical-shaped particles, $15 \mathrm{~g}$ of $\alpha$-FeOOH was placed in a Teflon-lined stainless steel autoclave (San-ai Kagaku Co., Ltd., Nagoya, Japan) with a capacity of $50 \mathrm{~mL}$. The autoclave was then filled with $48 \mathrm{~g}$ of the EG-water mixed solvent (water concentration-9 vol. \%). After the autoclave was sealed, it was heated at $200{ }^{\circ} \mathrm{C}$ for $24 \mathrm{~h}$. The resultant $\mathrm{Fe}_{3} \mathrm{O}_{4}$ microparticles were repeatedly washed with water and ethanol and dried in a vacuum oven at $50{ }^{\circ} \mathrm{C}$ for $24 \mathrm{~h}$. After drying, the weights of the microparticles were measured to calculate the yield. The octahedral-shaped particles were prepared by the same procedure except for the water content ( $12 \mathrm{vol} . \%)$ and the aging time ( $48 \mathrm{~h})$. The yield of these syntheses was ca. $86 \%$. The loss was mainly due to the microparticles lost during the washing.

\subsection{Preparation of $\mathrm{Fe}_{3} \mathrm{O}_{4}$ Microparticle-Based Suspensions}

EG was used as a carrier liquid. Spherical and octahedral $\mathrm{Fe}_{3} \mathrm{O}_{4}$ microparticles were dispersed in the EG via shaking and ultrasonication to prepare two different suspensions. The concentration of the microparticles in both fluids was 10 vol. \%.

\subsection{Characterization of $\mathrm{Fe}_{3} \mathrm{O}_{4}$ Microparticles and Evaluation of MR Fluids}

The morphologies of the as-synthesized samples were observed by field-emission scanning electron microscopy (FE-SEM, SU-70, Hitachi High-Tech). Their phase structures were analyzed by XRD (Multiflex, Cu-K $\alpha, 40 \mathrm{kV}$ and $40 \mathrm{~mA}$, Rigaku, Tokyo, Japan). DC magnetization was measured at room temperature with a conventional superconducting quantum interference device magnetometer (MPMS-XL, Quantum Design, San Diego, CA, USA). Steady MR responses of the $\mathrm{Fe}_{3} \mathrm{O}_{4}$ microparticle-based suspensions were measured at room temperature, using a magnetic-field-applicable parallel-disk sensor with an electromagnetic system (MR-101N, EKO Instruments, Tokyo, Japan) attached to a high-precision rheometer (RheoStress RS-150, HAAKE, Germany). A parallel-plate fixture with a diameter of $20 \mathrm{~mm}$ was used, and the gap was set to $300 \mu \mathrm{m}$. A magnetic field was applied perpendicular to the shear flow direction. Current control regulated the generated magnetic field 
from 0 to $239 \mathrm{kA} / \mathrm{m}$. The samples stood for a few seconds after application of the magnetic fields, and then the steady-state and oscillatory shear measurements were performed at room temperature. In steady-state measurement, the samples were sheared at shear rates varying from 1 to $1,000 \mathrm{~s}^{-1}$ and the corresponding shear stresses were recorded. In the oscillatory shear measurement, an oscillatory shear stress was applied with an amplitude ranging between $10^{-1}$ and $10^{3} \mathrm{~Pa}$ at a constant frequency of $1 \mathrm{~Hz}$.

Supplementary Materials: Supplementary materials can be found at http://www.mdpi.com/1422-0067/20/15/ 3617/s1.

Author Contributions: H.A. synthesized $\mathrm{Fe}_{3} \mathrm{O}_{4}$ microparticles and their MR fluids. T.N., K.S., and Y.S. performed the characterizations of the $\mathrm{Fe}_{3} \mathrm{O}_{4}$ microparticles. M.N. measured MR response. H.A. analyzed the data and drafted the manuscript based on discussion with T.N., K.S., Y.S., and M.N., H.A directed the work.

Funding: This study was supported by JSPS KAKENHI Grant Number JP17H03404 for Basic Research: Category B.

Acknowledgments: The authors thank Kuruma, Horinouchi, and Yoshida for the technical support provided by them.

Conflicts of Interest: The authors declare no conflict of interest.

\section{References}

1. Carlson, J.D.; Jolly, M.R. MR fluid, foam and elastomer devices. Mechatronics 2000, 10, 555-569. [CrossRef]

2. Murakami, T.; Sakai, M.; Nakano, M. Study on the development of passive MR damper with displacement-dependent damping characteristics. J. Fluid Sci. Technol. 2010, 5, 985-992. [CrossRef]

3. Kikuchi, T.; Noma, J.; Akaiwa, S.; Uechima, Y. Response time of magnetorheological fluid-based haptic devices. J. Intell. Materal Syst. Struct. 2016, 27, 859-865. [CrossRef]

4. Kikuchi, T.; Tanaka, T.; Anzai, K.; Hosaka, M.; Niino, K. Evaluation of line-tracing controller of intelligently controllable walker. Adv. Robot. 2013, 27, 493-502. [CrossRef]

5. Park, B.J.; Fang, F.F.; Choi, H.J. Magnetorheology: Materials and application. Soft Matter 2010, 16, 5246-5252. [CrossRef]

6. Ashtiani, M.; Hashemabadi, S.H.; Ghaffari, A. A review on the magnetorheological fluid preparation and stabilization. J. Magn. Magn. Mater. 2015, 374, 716-730. [CrossRef]

7. Lemaire, E.; Meunier, A.; Bossis, G.; Liu, J.; Felt, D.; Bashtovoi, P.; Matoussevitch, N. Influence of the particle size on the rheology of magnetorheological fluids. J. Rheol. 1995, 39, 1011-1020. [CrossRef]

8. Lopez-Lopez, M.T.; Kuzhir, P.; Meunier, A.; Bossis, G. Synthesis and magnetorheology of suspensions of submicron-sized cobalt particles with tunable particle size. J. Phys. Condens. Matter 2010, 22, 324106. [CrossRef]

9. Pei, L.; Pang, H.; Chen, K.; Xuan, S.; Gong, X. Simulation of the optimal and wall thickness of hollow $\mathrm{Fe}_{3} \mathrm{O}_{4}$ microspheres in magnetorheological fluids. Soft Mater. 2018, 15, 5080-5091. [CrossRef]

10. Bae, D.H.; Han, W.J.; Gao, C.Y.; Dong, Y.Z.; Choi, H.J. Preparation and magnetorheological response of triangular-shaped single-crystalline magnetite particle-based magnetic fluid. IEEE Tans. Mag. 2018, 54, 2001504.

11. Han, S.; Choi, J.; Seo, Y.P.; Park, J.I.; Choi, H.J. High-performance magnetorheological suspensions of pickering-emulsion-polymerized polystyrene/ $\mathrm{Fe}_{3} \mathrm{O}_{4}$ particles with enhanced stability. Langmuir 2018, 43, 2807-2814. [CrossRef] [PubMed]

12. Wu, Z.; Yang, S.; Wu, W. Shape controlled inorganic nanoparticles from solution. Nanoscale 2016, 8, 1237-1259. [CrossRef] [PubMed]

13. Qiao, L.; Fu, Z.; Ghosen, J.; Zeng, M.; Stebbins, J.; Pasad, P.N.; Swihart, M.T. Standardizing size-and shape-controlled synthesis of monodisperse magnetite $\left(\mathrm{Fe}_{3} \mathrm{O}_{4}\right)$ nanocrystals by identifying and exploiting effects of organic impurities. ACS Nano. 2017, 11, 6370-6381. [CrossRef] [PubMed]

14. Singh, G.; Chan, H.; Gelman, E.; Repnin, N.; Karl, P.; Kajn, R. Self-assembly of magnetite nanocubes into helical superstructures. Science 2014, 345, 1149-1153. [CrossRef] [PubMed]

15. Lanerisheth, Z.; Upadhyay, R.V. Influence of particle shape on the magnetic and steady shear magnetorheological properties of nanoparticles based MR fluids. Smart Mater. Struct. 2017, 26, 054008. [CrossRef] 
16. Jung, H.S.; Choi, H.J. Hydrothermal fabrication of octahedral-shaped $\mathrm{Fe}_{3} \mathrm{O}_{4}$ nanoparticles and their magnetorheological response. J. Appl. Phys. 2015, 117, 17E708. [CrossRef]

17. Fievet, F.; Lagier, J.P.; Blin, B.; Beaudoin, B.; Figlarz, M. Homogeneous and heterogeneous nucleations in the polyol process for the preparation of micron and submicron size metal particles. Solid Sate Ion. 1989, 32, 198-205. [CrossRef]

18. Schwertmann, U.; Cornell, R.M. Iron Oxides in the Laboratory, 2nd ed.; WILEY-VCH: Weinheim, Germany, 2000; pp. 27-32.

19. Vereda, F.; de Vicente, J.; del Puerto Morales, M.; Rull, F.; Hidalgo-Alvarez, R. Synthesis and Characterization of Single-Domain Monocrystalline Magnetite Particles by Oxidative Aging of $\mathrm{Fe}(\mathrm{OH})_{2}$. J. Phys. Chem. C. 2008, 115, 5843-5849. [CrossRef]

20. Domingo, C.; Rodriguez-Clemente, R.; Blesa, M. Morphological properties of $\alpha$-FeOOOG, $\gamma$-FeOOH and $\mathrm{Fe}_{3} \mathrm{O}_{4}$ obtained by oxidation of aqueous Fe(II) solutions. J. Colloid. Inter. Sci. 1994, 165, 244-252. [CrossRef]

21. Yamanaka, S.; Abe, H.; Naito, M.; Fujimoto, T.; Kuga, Y. Colloidal dispersibility of fatty acid-capped iron nanoparticles and its effect on static and dynamic magnetorheological response. Colloids and Surfaces A: Physicochem. Eng. Aspects. 2012, 415, 239-246. [CrossRef]

22. Vereda, F.; Segovia-Gutierrez, J.P.; de Vicente, J.; Hidalgo-Alvarez, R. Faceted particles: An approach for the enhancement of the elasticity and the yield-stress of magnetorheological fluids. J. Appl. Phys. 2016, 108, 211904. [CrossRef]

23. Byrne, J.M.; Telling, N.D.; Coker, V.S.; Pattrick, R.A.D.; van der Laan, G.; Arenholz, E.; Tuna, F.; Lloyd, J.R. Control of nanoparticle size, reactivity and magnetic production during the bioproduction of magnetite by geobacter sulfurreducens. Nanotechnology 2011, 22, 455709. [CrossRef] [PubMed]

24. Eguchi, M.; Mitsui, D.; Wu, H.L.; Sato, R.; Teranishi, T. Simple reductant concentration-dependent shape control of polyhedral gold nanoparticles and their plasmonic properties. Langmuir 2012, 28, 9021-9026. [CrossRef] [PubMed]

25. Stefansson, A. Iron(III) hydrolysis and solubility at $25^{\circ} \mathrm{C}$. Environ. Sci. Technol. 2007, 41, 6117-6123. [PubMed]

26. Baumgartner, J.; Dey, A.; Bomans, P.H.H.; Coadou, C.; Fratz, P.; Sommerdijk, N.A.J.M.; Faivre, D. Nucleation and growth of magnetite from solution. Nat. Mater. 2013, 12, 310-314. [CrossRef] [PubMed]

27. Deng, H.; Li, X.; Peng, Q.; Wang, X.; Chen, J.; Li, Y. Monodisperse magnetite single-crystal ferrite microspheres. Angew. Chem. Int. Ed. 2005, 44, 2782-2785. [CrossRef] [PubMed]

28. Xuan, S.; Wang, Y.-X.J.; Yu, J.C.; Leung, K.C.-F. Tuning the grain size and particle size of superparamagnetic $\mathrm{Fe}_{3} \mathrm{O}_{4}$. Chem. Mater. 2009, 21, 5079-5087. [CrossRef]

29. Sugimoto, T.; Matijevic, E. Formation of uniform spherical magnetite particles by crystallization from ferrous hydroxide gels. J. Colloid. Inter. Sci. 1980, 74, 227-243. [CrossRef]

30. Park, J.; Joo, J.; Kwon, S.G.; Jang, Y.; Hyeon, T. Synthesis of monodispersed spherical nanocrystals. Angew. Chem. Int. Ed. 2007, 46, 4630-4660. [CrossRef]

31. Rodriguez-Gonzalez, B.; Vereda, F.; de Vicente, J.; Hidalgo-Alvarez, R. Rough and hollow spherical magnetite microparticles; revealing the morphology, internal structure, and growth mechanism. J. Phys. Chem. C 2013, 117, 5397-5406. [CrossRef]

32. Sugimoto, T.; Sakata, K.; Muramatsu, A. Formation mechanism of monodispersed pseudocubic $\alpha-\mathrm{Fe}_{2} \mathrm{O}_{3}$ particles from condensed ferric hydroxide gel. J. Colloid. Inter. Sci. 1993, 159, 372-382. [CrossRef] 